\title{
A survey of bolus tube feeding prevalence and practice in adult patients requiring home enteral tube feeding
}

Gary P. Hubbard ${ }^{1 *}$, Sophie Andrews ${ }^{1}$, Sean White ${ }^{2}$, Gary Simpson ${ }^{2}$, Sarah Topen $^{3}$, Lindsay Carnie ${ }^{3}$, Claire Murphy ${ }^{4}$, Rhian Collins ${ }^{5}$, Judith Davies ${ }^{6}$, Annalisa Owen ${ }^{6}$, Julie Barker ${ }^{7}$, Lisa Green ${ }^{8}$, Ileen Patel ${ }^{9}$, Joanne Ridgway 9 , Jo Lenchner ${ }^{9}$, Julie Faerber ${ }^{9}$, Lorna Pearce ${ }^{9}$, Hannah Meanwell ${ }^{10}$, Natalie Kominek ${ }^{11}$, Lucy Stark $^{11}$, Heather Best ${ }^{11}$, Rebecca Simons ${ }^{1}$, Tessa Cross $^{1}$ and Rebecca J. Stratton ${ }^{1,12}$

${ }^{1}$ Medical Affairs, Nutricia Ltd, Wiltshire BA14 OXQ, UK

${ }^{2}$ Northern General Hospital, Sheffield S5 7AU, UK

${ }^{3}$ Huddersfield Royal Infirmary, Lindley, Huddersfield HD3 3EA, UK

${ }^{4}$ The Vale Centre for Health and Care, Alexandria G83 OUE, UK

${ }^{5}$ Aneurin Bevan Health Board, Royal Gwent Hospital, Newport NP2O 2UB, UK

${ }^{6}$ Aneurin Bevan Health Board, St Cadoc's Hospital, Newport NP18 3XQ, UK

${ }^{7}$ University Hospital Bristol NHS Foundation Trust, Bristol BS1 3NU, UK

${ }^{8}$ Brighouse Health Centre, Lawson Road, Calderdale HD6 1NY, UK

${ }^{9}$ Home Enteral Nutrition Team, Lewisham and Greenwich NHS Trust, Waldron Health Centre, Amersham Vale, New Cross, London SE14 6LD, UK

${ }^{10}$ Nottingham University Hospitals NHS Trust, Nottingham NG5 1PB, UK

${ }^{11}$ The Great Western Hospital, Swindon SN3 6BB, UK

${ }^{12}$ Faculty of Medicine, University of Southampton, Southampton SO16 6YD, UK

(Submitted 9 April 2019 - Final revision received 15 August 2019 - Accepted 19 August 2019)

\section{Abstract}

Anecdotal evidence suggests the use of bolus tube feeding is increasing in the long-term home enteral tube feed (HETF) patients. A crosssectional survey to assess the prevalence of bolus tube feeding and to characterise these patients was undertaken. Dietitians from ten centres across the UK collected data on all adult HETF patients on the dietetic caseload receiving bolus tube feeding ( $n 604,60 \%$ male, age 58 years). Demographic data, reasons for tube and bolus feeding, tube and equipment types, feeding method and patients' complete tube feeding regimens were recorded. Over a third of patients receiving HETF used bolus feeding (37\%). Patients were long-term tube fed (4.1 years tube feeding, 3.5 years bolus tube feeding), living at home ( $71 \%$ ) and sedentary (70\%). The majority were head and neck cancer patients (22\%) who were significantly more active $(79 \%)$ and lived at home $(97 \%)$, while those with cerebral palsy $(12 \%)$ were typically younger (age 31 years) but sedentary (94\%). Most patients used bolus feeding as their sole feeding method (46\%), because it was quick and easy to use, as a top-up to oral diet or to mimic mealtimes. Importantly, oral nutritional supplements (ONS) were used for bolus feeding in $85 \%$ of patients, with $51 \%$ of these being compact-style ONS $(2.4 \mathrm{kcal}(10.0 \mathrm{~kJ}) / \mathrm{ml}, 125 \mathrm{ml})$. This survey shows that bolus tube feeding is common among UK HETF patients, is used by a wide variety of patient groups and can be adapted to meet the needs of a variety of patients, clinical conditions, nutritional requirements and lifestyles.

Key words: Bolus feeding: Community nutrition: Enteral feeding: Home feeding: Tube feeding

Enteral tube feeding is a valuable method of providing nutrition support in the management of both acute and chronic illnesses in patients with a functioning gastrointestinal tract in whom oral intake is contraindicated or insufficient to meet the nutritional requirements ${ }^{(1)}$. Advancements in technology and the increasing pressure for costly healthcare to be moved out of acute hospitals and in to the community have meant more patients are now receiving enteral tube feeding in their own homes ${ }^{(2-5)}$. In the

Abbreviations: BANS, British Artificial Nutrition Survey; CVA, cerebrovascular accident; HETF, home enteral tube feed; MS, multiple sclerosis; ONS, oral nutritional supplements.

* Corresponding author: Gary P. Hubbard, email gary.hubbard@nutricia.com 
UK, it is estimated that over 23000 adults receive communitybased, long-term home enteral tube feeding $(\mathrm{HETF})^{(3,5)}$, and HETF incidence across Europe has been estimated to be between 62 and 457 new patients per million inhabitants per year $^{(6-8)}$. The disparity between countries and regions is likely due to the differences in clinical practice and healthcare systems as well as economic factors ${ }^{(6)}$. Currently in the UK, cancer (predominantly head, neck and gastrointestinal) and neurological disorders are the most prevalent conditions among adult patients receiving HETF and most are elderly ( $>70$ years) and have high levels of dependency ${ }^{(3,5)}$.

Today, commercially available, nutritionally complete enteral tube feeds are most commonly administered continuously over $24 \mathrm{~h}$ or intermittently (smaller volumes provided intermittently through the day) via an automated feeding pump during the day or night at various feeding rates ${ }^{(9)}$. Bolus tube feeding, however, is the administration of a predetermined volume of feed at specified intervals over a relatively short period of time and is typically delivered via syringe (with or without the use of a plunger) or in some cases via a feeding pump set to a high rate $^{(10)}$. However, varying volumes $(200-750 \mathrm{ml}$ ) and feeding periods (5-45 $\mathrm{min}$ ) have previously been used to define bolus tube feeding ${ }^{(10-14)}$.

Historically, gravity (drip) and bolus tube feeding were the primary methods of tube feeding and remain so in many parts of Europe $^{(6,15)}$. In the UK, these methods were superseded by automated feeding pumps, the usage of which has risen dramatically in the past 50 years, with previous studies finding that the majority of HETF patients in the UK utilise them ${ }^{(6,16)}$. However, recent anecdotal evidence suggests that the use of bolus tube feeding is increasing among certain patient groups ${ }^{(17,18)}$. There are several potential reasons for this, such as bolus tube feeding being more physiological, reflecting a regular eating pattern ${ }^{(19,20)}$, it being easier to adapt to the home environment and to the lifestyles of more mobile patients ${ }^{(21)}$. Furthermore, while some have previously argued that continuous tube feeding is better tolerated ${ }^{(22-24)}$, more recent studies have found no significant differences in safety and tolerance between continuous and bolus tube feeding ${ }^{(25-27)}$. As such, some clinical guidelines recommend bolus tube feeding as an appropriate option for HETF patients ${ }^{(10,28)}$. However, there is little or no published data on the extent of the use of bolus tube feeding regimens, the characteristics of these patients and the feeding regimens used. Therefore, this cross-sectional survey of current dietetic practice aimed to assess the point prevalence of the use of bolus tube feeding (either as the sole feeding method or in conjunction with other regimens), characterise the patients that receive bolus tube feeding and explore the types of feeding regimens used.

\section{Methods \\ Participants}

Twenty-two large adult HETF services from across the UK were approached to take part in the survey, of which dietitians from ten centres (Aneurin Bevan Home Enteral Feeding Service, Newport; Brighouse Health Centre, Calderdale; Home Enteral Nutrition (HEN) Team, Lewisham and Greenwich National
Health Service (NHS) Trust; Huddersfield Royal Infirmary; Northern General Hospital, Sheffield; Nottingham University Hospitals; Royal Gwent Hospital, Newport; The Great Western Hospital, Swindon; The Vale Centre for Health and Care, Alexandria; and University Hospital, Bristol) completed a standardised data collection form (see online Supplementary material) for each adult bolus tube feeding patient on the dietitians' HETF caseload between December 2015 and March 2016 from their dietetic patient records. Patients were included if they were aged 18 years and over at the start of the period and receiving bolus tube feeding via any method. Patients were excluded if they received only additional fluids and/or medication as boluses.

\section{Approvals}

Permission was granted by the NHS research and development department of each NHS Trust involved in this survey of routine practice from dietetic notes and patient consent was obtained where required. All collected data were anonymised.

\section{Data collection}

Standardised data collection forms recorded demographic data (patient's age, working status (full-time, part-time, retired, not working, other), residential status (own/family home, sheltered housing, residential home, nursing home), activity level (based on the six categories used for physical activity level values ${ }^{(29)}$ ), anthropometry (height/metre; weight/kilogram; BMI $/ \mathrm{kg} / \mathrm{m}^{2}$ )), medical diagnosis, time and reason for tube feeding and bolus tube feeding, feeding tube types (percutaneous endoscopic gastrostomy (PEG), radiologically inserted gastrostomy (RIG) and button/low-profile gastrostomy, nasogastric/jejunal (NG/NJ), tube size (Fr gauge)), and all feeding methods (bolus, continuous with pump, oral) and patient's complete bolus and other tube feeding regimens (feed types (tube feed; oral nutritional supplements (ONS); nutritional composition), rates, volumes, times, delivery method (pump, gravity, syringe, combination)) which were used to calculate mean nutritional intake from all enteral tube feeds (bolus tube feeds and any continuous tube feeds) as well as the proportion provided by bolus feeds only. The total number of HETF patients and the total number of bolus tube feeding patients were also recorded by each centre. The standardised data collection form was based on that used in previous other surveys of HETF populations ${ }^{(30-33)}$ and was tested with dietitians before use.

\section{Analysis}

The number of bolus tube feeding adult HETF patients was unknown. The total UK adult HETF population was estimated to be 23235 in $2015^{(3)}$. A sample size calculation (confidence level: $95 \%$, CI: 1.94 , accuracy: $50 \%$ ) provided a sample size of 2297. As this was approximately $10 \%$ of the total population that is typically considered appropriate for surveys and was practically possible, the aim of this survey was to include a total of $2300 \mathrm{UK}$ adult HETF patients from a variety of centres across the UK. Statistical analysis was completed using IBM SPSS Statistics (version 23). Data were analysed by whole bolus-fed population, diagnostic group (five most prevalent primary diagnoses) and feeding method: fully bolus tube fed (bolus tube feeding as main 
method of feeding, no continuous/intermittent tube feeds and no/ minimal oral intake) or partially bolus tube fed (combination of bolus tube feeding and continuous/intermittent tube feeding or oral intake). For questions where multiple answers could be given (reasons for enteral tube feeding, bolus tube feeding and the particular tube feeds used) answers were collated and are presented as a percentage of patients. For the diagnostic group analysis, oneway ANOVA with Bonferroni post hoc testing was used to compare the mean energy and protein intake, with independent-samples $t$ tests used to compare nutritional intake of fully $v$. partially bolus tube-fed patients. Ordinal data were analysed using a Kruskal-Wallis test with pairwise post hoc Mann-Whitney $U$ test to identify significant differences between diagnostic groups, and the $\alpha$ level was adjusted to $P<0.005$ to reduce the possibility of a type I error. $\chi^{2}$ and Fisher's exact test were used to analyse categorical data. Data are presented as means and standard deviations and $P$ value $<0.05$ was treated as significant, unless stated otherwise.

\section{Results}

\section{Whole bolus tube-fed population}

Dietitians from the ten centres reported 1832 adult HETF patients on their caseloads at the time of the survey and 675 (37\%) received tube feeding via the bolus method. Completed forms for 610 bolus tube-fed patients $(90 \%)$ were received (four centres completed forms for $100 \%$ patients; however, due to lack of time and clinical commitments the remaining centres were only able to complete forms for between 47 and $82 \%$ of patients). A total of 604 adult bolus tube-fed patients were eligible for analysis (exclusions $n 3$ water boluses only, $n 2$ continuous feeds only, $n 1<18$ years old). The number of bolus tube-fed patients per adult HETF centre varied from 9 to 164 .

The majority of bolus tube-fed patients were male (60\%), over 60 years of age $(55 \%$, mean 58 (SD 20) years), had received tube feeding for a mean of 4 (SD 5 , maximum 23) years and received bolus tube feeding for a mean of 3.5 (SD 4 , maximum 20) years. Less than a quarter of patients were 75 years and older (22\%) and $14 \%$ were under 30 years of age. Patient demographics can be seen in Table 1 . No differences in demographic data were observed between reporting HETF centres.

The majority of bolus tube-fed patients lived at home or in a family home (70 \%), and nearly all were found to be not working (61\%) or retired (34\%). Low levels of activity were seen overall, with over two thirds of bolus tube-fed patients (69\%) classed as sedentary (bed rest, chair or bed bound $48 \%$; very sedentary, mostly seated $21 \%$ ) (Table 2 ). The primary reasons for tube feeding were dysphagia/swallowing difficulties (68\%), poor oral intake (13\%) and 'nil by mouth' (9\%). PEG tube was the most common type among bolus tube feeding patients ( $72 \%)$, followed by a 'button' or low-profile gastrostomy tube (12\%) and an RIG tube ( $8 \%$ ), with very few patients having an NG/ $\mathrm{NJ}$ tube (2\%). The majority of tube gauge sizes were $15 \mathrm{Fr}$ $(47 \%)$ and 16 Fr $(27 \%)$

Bolus tube feeding as the only method of feeding was the most common ( $46 \%$; see section on fully bolus tube-fed
Table 1. Patient demographics of whole bolus-fed population ( $n 604)$ (Mean values and standard deviations; minimum and maximum values)

\begin{tabular}{lcccc}
\hline & Mean & SD & Minimum & Maximum \\
\hline Age (years) & 58 & 20 & 18 & 97 \\
Height $(\mathrm{m})$ & $1 \cdot 7$ & 0.2 & $1 \cdot 2$ & $2 \cdot 0$ \\
Weight $(\mathrm{kg})$ & $61 \cdot 7$ & 14.5 & 25 & 109 \\
BMl $\left(\mathrm{kg} / \mathrm{m}^{2}\right)$ & $22 \cdot 5$ & $4 \cdot 1$ & $12 \cdot 2$ & 40 \\
Time receiving tube feeding (years) & 4 & 5 & $0 \cdot 2$ & 24 \\
Time receiving bolus feeding (years) & $3 \cdot 5$ & 4 & $0 \cdot 1$ & 20 \\
\hline
\end{tabular}

patients), followed by bolus tube feeding and oral intake combined (32\%) and bolus and continuous tube feeding combined (16\%). Administering feed via syringe was the most frequently used bolus tube feeding method (51\%) ahead of gravity feeding ( $41 \%$ ) and bolus tube feeds given via pump (8\%) (Table 3). Bolus tube feeds were delivered between one and eight times per d.

The main reasons stated for choosing a bolus tube feeding regimen for the patients were for use as a top-up to oral diet (39\%), to mimic mealtimes (31\%), and that it was easy (29\%) and quick to use (23\%). The decision to use the bolus tube feeding method was reported to be mutual (dietitian and patient, $41 \%$ ) or dietitian led (35\%). Dietitians reported that the majority of patients found the bolus tube feeding equipment (giving sets and syringes or pumps) very easy (44\%) or moderately easy (25\%) to use.

The mean bolus tube feeding volume was 168 (SD 465) $\mathrm{ml} /$ bolus, with $125 \mathrm{ml}$ ( $n$ 369) and $200 \mathrm{ml}$ ( $n$ 260) volume being the most common due to the use of compact-style $(125 \mathrm{ml}$, $2.4 \mathrm{kcal}(10 \cdot 0 \mathrm{~kJ}) / \mathrm{ml})$ ONS and standard $(200 \mathrm{ml}, 1.5 \mathrm{kcal}$ $(6 \cdot 3 \mathrm{~kJ}) / \mathrm{ml}$ ) ONS, respectively (some patients used multiple ONS). Mean daily total bolus tube feed volume was 465 (sD 340, range 30-2000) $\mathrm{ml} / \mathrm{d}$.

Total mean energy intake from enteral tube feeding was 6272 (sD 2377) kJ/d or 25 (sD 11) kcal (105 (sD 46) kJ)/kg per d, with a mean of 85 (sD 30$) \%(5347 \mathrm{~kJ} / \mathrm{d}$ ) provided by bolus tube feeding. Total mean protein intake from enteral tube feeding was 61 (SD 22) $\mathrm{g} / \mathrm{d}$ or 1.0 (sD 0.4) g protein/ $\mathrm{kg}$ per $\mathrm{d}$, with a mean of 85 (SD 30) \% $(52 \mathrm{~g} / \mathrm{d})$ provided by bolus tube feeding. Mean total energy and protein intake from all enteral tube feeds were significantly higher in those who used shot-style ONS to bolus $(\leq 45 \mathrm{ml} /$ dose very-highenergy/protein module, mean 7531 (sD 2565) kJ/d, 66 (sD 22) g/d protein) than those who did not $(5987$ (sD 2234) kJ/d, 60 (sD 21) g/d protein, $P<0 \cdot 01$ ).

Nutritional feeds in the form of 125 or $200 \mathrm{ml}$ ONS were used by $85 \%$ of patients in their bolus tube feeding regimens, with over half of these ( $51 \%$ ) using a compact-style ONS and a further $18 \%$ using a shot-style ONS ( $\leq 45 \mathrm{ml}$, very-high-energy/protein module) (some patients used multiple feed types). However, $13 \%$ of all bolus tube feeds were commercially available enteral tube feeds (in $500-1500 \mathrm{ml}$ packs), of which most were $\geq 1.5 \mathrm{kcal}$ $(6.3 \mathrm{~kJ}) / \mathrm{ml}(57 \%)$ and contained fibre $(55 \%)$. The most common reasons for choosing a particular feed or feeds for bolus tube feeding were that they met the patient's requirements (36\%), were in a low or convenient volume (19\%) and because of tolerance reasons $(16 \%)$. Dietitians reported that most patients found the feeds very easy ( $45 \%$ ) or moderately easy to use (33\%). 
Table 2. Demographic characteristics of whole bolus-fed population, by primary diagnosis and by feeding method (Numbers of patients; mean values and standard deviations; percentages)

\begin{tabular}{|c|c|c|c|c|c|c|c|c|c|}
\hline \multirow[b]{2}{*}{ Characteristics } & \multicolumn{7}{|c|}{ Results by primary diagnosis } & \multicolumn{2}{|c|}{$\begin{array}{l}\text { Results by feeding } \\
\text { method }\end{array}$} \\
\hline & $\begin{array}{l}\text { Whole } \\
\text { population }\end{array}$ & $\begin{array}{l}\text { Head and } \\
\text { neck CA }\end{array}$ & CVA & $\begin{array}{l}\text { Cerebral } \\
\text { palsy }\end{array}$ & $\begin{array}{l}\text { Learning } \\
\text { difficulties }\end{array}$ & $\begin{array}{l}\text { Multiple } \\
\text { sclerosis }\end{array}$ & $\begin{array}{c}\text { Other } \\
\text { diagnoses }\end{array}$ & $\begin{array}{c}\text { Fully } \\
\text { bolus fed }\end{array}$ & $\begin{array}{l}\text { Partially } \\
\text { bolus fed }\end{array}$ \\
\hline$n$ & 604 & 130 & 98 & 70 & 45 & 44 & 217 & 279 & 325 \\
\hline Mean age (years) ${ }^{*}$ & 58 & 63 & 75 & 31 & 41 & 54 & 61 & 62 & 56 \\
\hline SD & 20 & 11 & 13 & 15 & 17 & 11 & 19 & 20 & 20 \\
\hline \multicolumn{10}{|l|}{ Residential status (\%) } \\
\hline Family home & 70 & 97 & 47 & 69 & 58 & 71 & 69 & 67 & 74 \\
\hline Sheltered housing & 2 & 2 & 2 & 4 & 0 & 0 & 1 & 2 & 2 \\
\hline Residential home & 5 & 0 & 1 & 14 & 24 & 2 & 2 & 5 & 4 \\
\hline Nursing home & 22 & 1 & 50 & 10 & 13 & 27 & 28 & 25 & 19 \\
\hline Other & 1 & 0 & 0 & 3 & 4 & 0 & 1 & 0 & 1 \\
\hline \multicolumn{10}{|l|}{ Working status (\%) } \\
\hline Working FT & 1 & 6 & 0 & 0 & 0 & 0 & 1 & 1 & 2 \\
\hline Working PT & 1 & 2 & 0 & 0 & 2 & 2 & 1 & 1 & 1 \\
\hline Retired & 34 & 48 & 63 & 1 & 2 & 14 & 35 & 39 & 31 \\
\hline Not working & 61 & 43 & 37 & 91 & 93 & 84 & 62 & 60 & 63 \\
\hline Other & 2 & 1 & 0 & 7 & 2 & 0 & 2 & 0 & 3 \\
\hline \multicolumn{10}{|l|}{ Activity level (\%) } \\
\hline Sedentary 1 & 48 & 3 & 68 & 74 & 67 & 93 & 46 & 52 & 46 \\
\hline Sedentary 2 & 21 & 18 & 18 & 21 & 22 & 5 & 28 & 21 & 22 \\
\hline Active 1 & 15 & 43 & 11 & 3 & 0 & 0 & 11 & 13 & 17 \\
\hline Active 2 & 12 & 32 & 1 & 3 & 4 & 0 & 11 & 11 & 13 \\
\hline Active 3 & 3 & 5 & 1 & 0 & 7 & 2 & 3 & 3 & 3 \\
\hline Active 4 & 0 & 0 & 0 & 0 & 0 & 0 & 1 & 0 & 0 \\
\hline
\end{tabular}

CA, cancer; CVA, cerebrovascular accident; FT, full-time; PT, part-time; Sedentary 1, bed rest, chair or bed bound; Sedentary 2 , very sedentary, mostly seated, little or no strenuous leisure activity; Active 1, seated work, with requirement to move around but no strenuous exercise; Active 2, standing work/light exercise; Active 3, moderate work/moderate exercise; Active 4, strenuous work/strenuous exercise.

* Mean age significantly different between diagnostic groups and between feeding method groups $(P<0.005)$.

Table 3. Feeding regimen characteristics of whole bolus-fed population, by primary diagnosis and by feeding method (Numbers of patients; percentages)

\begin{tabular}{|c|c|c|c|c|c|c|c|c|c|}
\hline \multirow[b]{2}{*}{ Characteristics } & \multicolumn{7}{|c|}{ Results by primary diagnosis } & \multicolumn{2}{|c|}{$\begin{array}{l}\text { Results by } \\
\text { feeding method }\end{array}$} \\
\hline & $\begin{array}{l}\text { Whole } \\
\text { population }\end{array}$ & $\begin{array}{c}\text { Head } \\
\text { and neck } \\
\text { CA }\end{array}$ & CVA & $\begin{array}{l}\text { Cerebral } \\
\text { palsy }\end{array}$ & $\begin{array}{l}\text { Learning } \\
\text { difficulties }\end{array}$ & $\begin{array}{l}\text { Multiple } \\
\text { sclerosis }\end{array}$ & $\begin{array}{l}\text { All other } \\
\text { diagnoses }\end{array}$ & $\begin{array}{c}\text { Fully } \\
\text { bolus } \\
\text { fed }\end{array}$ & $\begin{array}{l}\text { Partially } \\
\text { bolus } \\
\text { fed }\end{array}$ \\
\hline$n$ & 604 & 130 & 98 & 70 & 45 & 44 & 217 & 279 & 325 \\
\hline Bolus tube feeding only (\%) & 46 & 45 & 57 & 41 & 39 & 52 & 45 & 100 & 0 \\
\hline \multicolumn{10}{|l|}{ Main feeding regimen (\%) } \\
\hline Bolus only & 46 & 45 & 57 & 41 & 39 & 52 & 45 & $100^{*}$ & 0 \\
\hline Bolus and oral & 32 & 42 & 22 & 30 & 34 & 24 & 32 & 0 & $60^{*}$ \\
\hline Continuous pump & 3 & 3 & 1 & 3 & 5 & 0 & 3 & 0 & $5^{\star}$ \\
\hline Pump and bolus & 16 & 6 & 18 & 21 & 16 & 24 & 18 & 0 & $30^{*}$ \\
\hline Pump, bolus and oral & 3 & 4 & 1 & 4 & 7 & 0 & 2 & 0 & $5^{\star}$ \\
\hline \multicolumn{10}{|l|}{ Mode of bolus delivery (\%) } \\
\hline Pump & 8 & 0 & 3 & 23 & 21 & 7 & 7 & 9 & 7 \\
\hline Gravity & 41 & 50 & 44 & 33 & 39 & 37 & 38 & 40 & 41 \\
\hline Syringe & 51 & 50 & 53 & 43 & 41 & 56 & 54 & 50 & 52 \\
\hline Combination & 1 & 1 & 0 & 1 & 0 & 0 & 1 & 1 & 0 \\
\hline \multicolumn{10}{|l|}{ ONS type (\%) } \\
\hline Using ONS (total)† & 85 & 95 & 84 & 71 & 76 & 77 & 87 & $79 \ddagger$ & $90 \ddagger$ \\
\hline Using compact style ONS† & 51 & 51 & 55 & 33 & 27 & 43 & 56 & 46 & 51 \\
\hline Using shot-style ONS† & 18 & 19 & 13 & 14 & 9 & 21 & 23 & 20 & 17 \\
\hline
\end{tabular}

CA, cancer; CVA, cerebrovascular accident; ONS, oral nutrition supplement.

* Significant difference in percentage of patients using each feeding method between fully and partially bolus-fed patients $\left(P<0.001 ; \chi^{2}\right)$.

† Some patients used multiple feed types.

$\ddagger$ Significant difference in percentage of patients using ONS between fully and partially bolus-fed patients $(P<0.001$; Fisher's exact test). 
Table 4. Nutritional intake from enteral feeds of fully and partially bolus-fed patients $\dagger$

(Mean values and standard deviations)

\begin{tabular}{|c|c|c|c|c|}
\hline & \multicolumn{2}{|c|}{ Fully bolus fed ${ }^{\star}$} & \multicolumn{2}{|c|}{$\begin{array}{l}\text { Partially bolus } \\
\text { fed }\end{array}$} \\
\hline & Mean & SD & Mean & SD \\
\hline $\begin{array}{l}\text { Total daily energy intake from all } \\
\text { enteral feeds }(\mathrm{kJ} / \mathrm{d})\end{array}$ & 6933 & 2000 & 5699 & 2523 \\
\hline $\begin{array}{l}\text { Total daily protein intake from all } \\
\text { enteral feeds }(\mathrm{g} / \mathrm{d})\end{array}$ & $66 \cdot 0$ & $17 \cdot 8$ & $56 \cdot 1$ & 23.5 \\
\hline $\begin{array}{l}\text { Daily energy contributed by bolus } \\
\text { feeds only }(\mathrm{kJ} / \mathrm{d})\end{array}$ & 6933 & 1992 & 3778 & 2393 \\
\hline $\begin{array}{l}\text { Daily protein contributed by bolus } \\
\text { feeds only }(\mathrm{g} / \mathrm{d})\end{array}$ & $66 \cdot 0$ & $17 \cdot 8$ & $36 \cdot 4$ & $23 \cdot 1$ \\
\hline $\begin{array}{l}\text { Daily energy intake from all enteral } \\
\text { feeds by weight }(\mathrm{kJ} / \mathrm{kg} \text { per } \mathrm{d})\end{array}$ & 118.4 & $39 \cdot 3$ & $96 \cdot 2$ & $46 \cdot 9$ \\
\hline $\begin{array}{l}\text { Daily protein intake from all enteral } \\
\text { feeds by weight }(\mathrm{g} / \mathrm{kg} \text { per } \mathrm{d})\end{array}$ & 1.12 & 0.3 & 0.94 & 0.4 \\
\hline
\end{tabular}

* Significant difference between fully and partially bolus-fed patients for all parameters $(P<0.001)$.

† $n 600$ ( $n 4$ insufficient data provided to calculate intake).

\section{Fully bolus tube-fed patients}

The fully bolus tube-fed patients ( $n$ 279) were significantly older (mean 62 (sD 20) years) than partially bolus tube-fed patients (mean 56 (sD 20) years, $P=0 \cdot 002$ ), with a much greater proportion over 75 years of age ( $28 v .16 \%$ ), due to the majority of cerebrovascular accident (CVA) patients (mean age 75 years) being fully bolus tube fed (57\%). Despite this, time receiving bolus tube feeding was similar between fully and partially bolus tube-fed patients, as were activity level, working and residential status. Most multiple sclerosis (MS) patients (52\%) received bolus tube feeding only, compared with a smaller proportion of bolus tube-fed head and neck cancer patients ( $45 \%$ ), cerebral palsy patients ( $41 \%$ ) and learning difficulties patients (39\%) (Table 3). Total mean intake of energy and protein from enteral tube feeding were significantly higher in fully bolus tube-fed patients compared with partially bolus tube-fed patients (Table 4), despite no significant differences in primary diagnosis or activity level, most likely due to the majority of the partially bolus tube-fed patients receiving a combination of bolus tube feeding and oral intake (60\%, Table 3$)$.

\section{Bolus-fed population by primary diagnosis}

The most common primary diagnosis in the bolus tube-fed population was head and neck cancer (22\%), followed by CVA (16\%), cerebral palsy (12\%), learning difficulties (7\%) and MS (7\%) (Table 2). Other diagnoses captured included brain injury (7\%), other central nervous system disorders (5\%), motor neurone disease (5\%) and other neurodegenerative conditions (5\%). Indeed, two HETF services reported only head and neck cancer patients in their bolus feeding population ( $n 10$ and 9).

Bolus tube-fed head and neck cancer patients ( $n$ 130) were significantly more active than the other four most prevalent conditions, with $80 \%$ classed as active $(P<0.005)$. Almost all bolus tube-fed head and neck cancer patients lived at home or in a family home (97\%) and were the only subgroup to have patients remaining in full-time work ( $6 \%$ ). Despite being the second oldest group in the survey (mean age 63 (SD 11) years), only one head and neck cancer patient lived in a nursing home (see Table 2). A higher percentage of RIG tubes were found in bolus tube-fed head and neck cancer patients (17\%) compared with any other condition, and almost all used ONS in their bolus tube feeding regimens (95\%) (Table 3). Mean energy and protein intake from total enteral tube feeding was found to be significantly higher in head and neck cancer patients $(P<0 \cdot 001)$ compared with the other four most prevalent diagnoses, with the exception of protein intake by MS patient $(P=0.448)$ (see Fig. 1). Energy and protein contributed by bolus tube feeds alone was also significantly higher in head and neck cancer patients $(P<0.01)$ compared with the four other primary diagnoses.

Bolus tube-fed CVA patients were the oldest of the five most prevalent conditions with a mean age of 75 (SD 13) years, with half living in a nursing home (50\%) and more using only bolus tube feeding as their main tube feeding method (57\%) compared with any other condition. They had the highest usage of compact-style ONS ( $55 \%$ ); while the majority were bolus tube fed via syringe (53\%), they had the highest rate of gravity bolus tube feeding (44\%) (see Table 3). Bolus tube-fed cerebral palsy patients, despite being the youngest of the five most common conditions (mean age 31 (SD 15) years) had received bolus tube feeding for the longest (mean 7 ( $\mathrm{SD}$ 5) years); none were reported to be working but $7 \%$ were in education, the vast majority were sedentary (95\%) and nearly a quarter administered bolus tube feeds via pump (23\%).

Bolus tube-fed patients with learning difficulties displayed characteristics mostly similar to bolus tube-fed cerebral palsy patients; however, a small amount worked part time (2\%) and they had the highest activity level ( $7 \%$ moderate-strenuous work/exercise). Bolus tube-fed MS patients lived mostly at home (71\%), the mean age was relatively young (54 (sD 11) years), over a quarter lived in a nursing home (27\%), most were not working (84\%), they had the highest level of inactivity (98\% sedentary, significantly higher than all other conditions except cerebral palsy $(P<0.005))$ and the vast majority were bed or chair bound $(93 \%)$.

For the other diagnoses captured in the survey (brain injury, other central nervous system disorders, motor neurone disease and other neurodegenerative conditions), bolus tube-fed patient demographics and nutritional intakes were either similar to that of the whole bolus tube-fed group or not considered representative of the condition as the number of patients in the survey was too low.

\section{Discussion}

To the best of our knowledge, this is the first and largest crosssectional survey to assess the extent of use of bolus tube feeding in community-based enterally tube-fed patients. This survey found that the use of bolus tube feeding is widespread in the UK, with over one third of HETF patients using bolus tube feeding as part or all of their tube feeding regimen. Bolus tube feeding patients were mostly older (over 60 years), receiving tube feeding and bolus tube feeding long-term, and had a wide variety of conditions. The use of ONS in bolus tube feeding 
(a)

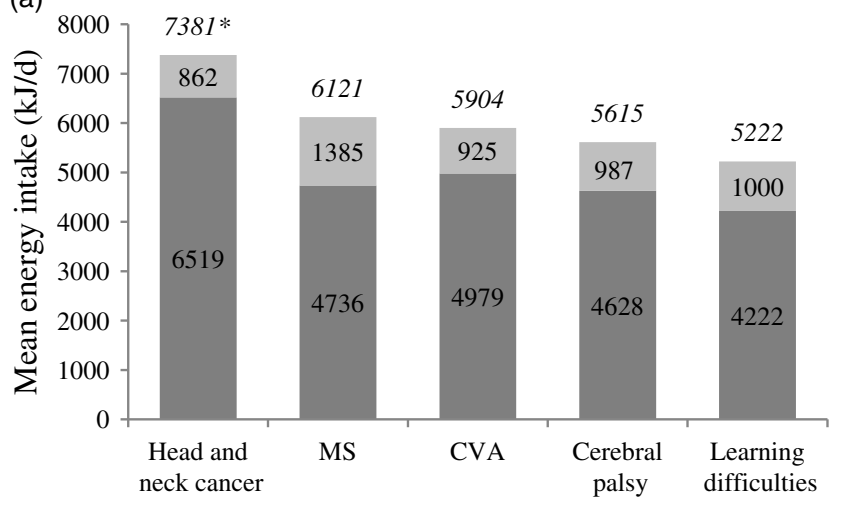

(b)

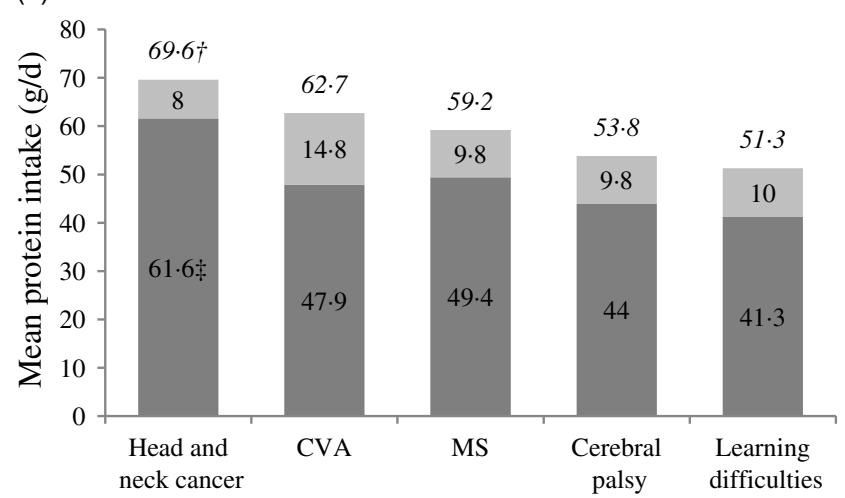

Fig. 1. Mean daily energy $(\mathrm{kJ} / \mathrm{d})$ and protein $(\mathrm{g} / \mathrm{d})$ intake from enteral feeding by primary diagnosis. Mean energy (a) and protein (b) intake from total enteral tube feeding (full bar and top number in italics), mean energy and protein intake provided by bolus feeding method (dark grey portion of bar and number) and mean energy and protein intake provided by continuous feeding method (light grey portion of bar and number). MS, multiple sclerosis; CVA, cerebrovascular accident. * Mean energy intake significantly higher for head and neck cancer than four other main diagnostic groups $(P<0.05)$ for all enteral feeds and from bolus feeds only. $\dagger$ Mean protein intake from all enteral feeds significantly higher for head and neck cancer than CVA, cerebral palsy and learning difficulties $(P<0.05)$. $\ddagger$ Mean protein intake from bolus feeds significantly higher for head and neck cancer than four other main diagnostic groups $(P<0.05)$. $\square$, Bolus feeds; $\square$, continuous feeds.

was more extensive than recognised previously. Despite the potential for bolus tube feeding to better accommodate a more active lifestyle, low levels of activity and employment were observed in the group overall. Surprisingly, the most popular reasons for using bolus tube feeding were because it is quick and easy to use, supports oral intake and mimics mealtimes, rather than the need for mobility, which may indicate the importance for patients of family mealtimes and making feeding a part of normal life. The high proportion of patients using ONS to bolus tube feed indicates the convenience and variety of this feed presentation for bolus tube feeding, especially as most ONS are suitable as a sole source of nutrition. Enteral tube feeds are generally presented in larger plastic or foil packs designed for use with feeding pumps (500-1500 ml), whereas ONS typically packaged in $125-250 \mathrm{ml}$ bottles or cartons facilitate the bolus method of tube feeding in small-volume doses. The significantly higher energy intake of those using shot-style ONS ( $\leq 45 \mathrm{ml})$ suggests this style of feed may also have an important role in bolus tube feeding regimens, in particular for those with increased energy requirements.

While this is the first survey to look specifically at bolus tube feeding practices among HETF patients, the British Artificial Nutrition Survey (BANS), carried out by the British Association for Parenteral and Enteral Nutrition, audits community nutrition support across the UK, the findings of which support many of the findings of the current survey ${ }^{(3,5,34)}$. From the BANS data, head and neck cancer patients accounted for $34 \%$ of newly registered HETF patients in 2015, with central nervous system conditions including CVA and cerebral palsy accounting for $40 \%$, all closely resembling the findings presented here (head and neck cancer $22 \%$, CVA $16 \%$ and cerebral palsy $12 \%$ ), suggesting that the main diagnostic groups in this current survey are representative of the UK HETF population. Lifestyle demographics captured in BANS (residential status, activity level) were also similar to the current survey ${ }^{(5)}$, and recent published BANS data also reported high levels of independence and activity in the head and neck cancer subgroup $^{(34)}$. However, at present BANS does not collect data on enteral tube feeding methods or feeds, and it is hoped that the significant rates of bolus tube feeding revealed in this survey may lead to the consideration of bolus tube feeding as an area of focus in future BANS and other similar national surveys.

Importantly, this survey highlights the heterogeneity of bolus tube-fed patients as a group, though head and neck cancer was the most common diagnosis and notably differed from the other patient types in this survey, living almost exclusively at home with high activity levels and significantly higher energy and protein intake. Their age, lifestyles and the increased metabolic demand of their condition ${ }^{(35,36)}$ may all contribute to the need for higher nutritional intake in this group. It is likely that the adaptability, mobility and speed of use of the bolus tube feeding method appeal to this growing patient group, which is younger and more active, as bolus tube feeding negates the need for longtime periods attached to a feeding pump. In contrast, the high proportion of older (e.g. CVA) and less active (e.g. cerebral palsy and MS) patient groups also undertaking bolus tube feeding was a surprising and interesting outcome and suggests that the potential uses of bolus tube feeding, such as to top-up oral diet and mimic mealtimes, can benefit a wide range of patient types, highlighting the broad use of the bolus tube feeding method and its potential to help support many HETF patients.

In addition to the diverse population identified, this survey also demonstrated the level of variation in the use of the bolus tube feeding method. For most patients, bolus tube feeding alone providing all nutrition was the primary method of feeding; however, for others bolus tube feeding comprised only a small proportion of daily nutritional needs, as it was used in combination with continuous/intermittent tube feeding or to support oral intake to varying degrees (most commonly in head and neck cancer patients). Energy and protein intake were significantly higher in fully bolus tube-fed patients than in partially bolus tube-fed patients, as could be expected; however, these two groups did not vary significantly in most demographic variables. These similarities suggest there is no such thing as a typical bolus 
tube feeding patient, and that bolus tube feeding whether used solely or as part of a mixed regimen can have a role to play for many kinds of enterally tube-fed patients ${ }^{(37)}$.

To date, much of the published research of bolus tube feeding practices has focused on the administration of the tube feed and associated symptoms, usually in hospital settings. Many of these studies have found no significant differences between bolus and continuous tube feeding in key enteral feeding outcomes, including nutritional intake, safety and tolerance $e^{(26,27,38-40)}$. Some of the research in fact argues in favour of bolus tube feeding over continuous tube feeding from a biological standpoint, stating that continuous tube feeding is incompatible with human physiology as it does not stimulate the gastrointestinal tract into a fed response ${ }^{(13,14)}$. Studies by Stratton et al. have demonstrated that bolus tube feeding elicits a greater satiating effect and a hormone response more typical of the fed state compared with continuous tube feeding ${ }^{(19,20)}$, which would support the current survey's finding that many patients use bolus tube feeding to mimic mealtimes. Further research is needed into the possible physiological, psychological and social benefits of bolus tube feeding; however, as it has been shown in the current survey to be widely used long-term ( $\max 20$ years) by a diverse population of long-term HETF patients, we may conclude that it is both safe and well tolerated, with the potential benefits that it is quick and easy to use, or chosen because the patient wishes to be more active. This also supports the findings of Brotherton et al. who found patients and their carers appreciated the flexibility afforded by bolus tube feeding ${ }^{(41)}$. However, further research is required to understand the drivers for this growing trend in HETF practice.

This survey is not without limitations. A cross-sectional survey design only captures a moment in time and therefore may not be fully representative, and clinical practice may differ between regions and countries. All data were recorded by the dietitians, relying on patient dietetic notes; this was identified as the only appropriate method to enable the collection of data from a large number of patients. However, not all centres were able to capture data for every bolus tube-fed patient due to lack of time and clinical commitments, both of which may have led to underreporting. Potential selection bias of centres more willing to take part may also have led to overreporting or reporting bias, and though centres from across the UK took part, they may not be representative of the whole HETF population. All participating centres were general adult home enteral tube feeding services caring for a range of patient types, and so patients managed by specialist or tertiary centres will have been omitted. Furthermore, this survey did not explore bolus tube feeding in paediatric tube feeding populations, and original data were collected in the period 2015/2016, with further trends towards bolus feeding possibly occurring since this time.

This survey shows that bolus tube feeding is now used by over a third of long-term HETF patients in community practice in the UK with a variety of conditions and lifestyles. The diversity of the patient's conditions, feeding regimens and the reasons for using them described in this survey provides valuable insights to allow clinicians to explore ways of using bolus tube feeding in their own clinical practice. While this survey significantly contributes to our understanding of the bolus tube feeding patient group, there remains a paucity of literature regarding home enteral tube feeding and particularly bolus tube feeding patients. It is hoped that the results of this survey will encourage further research in this area, with inclusion of tube feeding methods in surveys, such as BANS throughout Europe and worldwide.

\section{Acknowledgements}

Special thanks to the all the dietetic teams who worked on this project.

This work was funded by Nutricia Ltd, Trowbridge, UK.

G. P. H., S. A., R. S., T. C. and R. J. S. are employees of Nutricia Ltd UK. No other conflicts of interest declared.

G. P. H. was involved with conceptualisation, methodology, validation, formal analysis, writing-original draft, writing-review and editing, supervision. S. A. contributed to formal analysis, writing-original draft, writing-review and editing, project administration. S. W., G. S., S. T., L. C., C. M., R. C., J. D., A. O., J. B., L. G., I. P., J. R., J. L., J. F., L. P., H. M., N. K., L. S. and H. B. were in charge of investigation, resources, writing review and editing. R. S. was involved with conceptualisation, methodology, validation, formal analysis, writing review and editing, visualisation, project administration. T. C. contributed to conceptualisation, methodology, validation, visualisation, supervision, project administration. R. J. S. was involved with conceptualisation, methodology, writing original draft, writing-review and editing, supervision.

\section{Supplementary material}

To view supplementary material for this article, please visit http://doi.org/10.1017/S000711451900223X

\section{References}

1. Stratton RJ, Green CJ \& Elia M (2003) Disease-Related Malnutrition: An Evidence-Based Approach to Treatment. Oxford: CABI Publishing.

2. Howard P \& Bowen N (2001) The challenges of innovation in the organization of home enteral tube feeding. J Hum Nutr Diet 14, 3-11.

3. BANS Report (2018) Home Enteral Tube Feeding (HETF) in Adults (2010-2015). A Report by the British Artificial Nutrition Survey (BANS) - A Committee of BAPEN. Redditch: British Association for Parenteral and Enteral Nutrition.

4. Ojo O (2015) The challenges of home enteral tube feeding: a global perspective. Nutrients 7, 2524-2538.

5. British Artifical Nutrition Survey (BANS) (2011) Annual BANS Report 2011: Artificial Nutrition Support in the UK 2000-2010. Redditch: BAPEN.

6. Hebuterne X, Bozzetti F, Moreno Villares JM, et al. (2003) Home enteral nutrition in adults: a European multicentre survey. Clin Nutr 22, 261-266.

7. Wanden-Berghe C, Matia Martin P, Luengo Perez LM, et al. (2014) Home enteral nutrition in Spain; NADYA registry 2011-2012. Nutr Hosp 29, 1339-1344.

8. Klek S, Pawlowska D, Dziwiszek G, et al. (2015) The evolution of home enteral nutrition (HEN) in Poland during five years after implementation: a multicentre study. Nutr Hosp 32, 196-201.

9. Gandy J (2014) Manuel of Dietetic Practice. 5th ed. Chichester: Wiley Blackwell. 
10. Merritt R, DeLegge MH, Holcombe B, et al. (2005) The ASPEN Nutrition Support Practice Manual. Silver Spring, MD: American Society for Parenteral and Enteral Nutrition.

11. Bowling TE, Cliff B, Wright JW, et al. (2008) The effects of bolus and continuous nasogastric feeding on gastro-oesophageal reflux and gastric emptying in healthy volunteers: a randomised three-way crossover pilot study. Clin Nutr 27, 608-613.

12. Heitkemper ME, Martin DL, Hansen BC, et al. (1981) Rate and volume of intermittent enteral feeding. J Parenter Enteral Nutr $\mathbf{5}, 125-129$.

13. Chowdhury AH, Murray K, Hoad CL, et al. (2016) Effects of bolus and continuous nasogastric feeding on gastric emptying, small bowel water content, superior mesenteric artery blood flow, and plasma hormone concentrations in healthy adults: a randomized crossover study. Ann Surg 263, 450.

14. Hooper MH \& Marik PE (2015) Controversies and misconceptions in intensive care unit nutrition. Clin Chest Med 36, 409-418.

15. Harkness L (2002) The history of enteral nutrition therapy. J Am Diet Assoc 102, 399-404.

16. Liley AJ \& Manthorpe J (2003) The impact of home enteral tube feeding in everyday life: a qualitative study. Health Soc Care Community 11, 415-422.

17. Zhang M, Hubbard J, Rudnicki SA, et al. (2013) Survey of current enteral nutrition practices in treatment of amyotrophic lateral sclerosis. e-SPEN J 8, e25-e28.

18. Kereena C \& Kumar CK (2015) Enteral nutrition support in patients with head and neck cancers being treated with radiotherapy and/or chemotherapy. Int J Med Res Rev 3, 428-435.

19. Stratton RJ, Stubbs RJ \& Elia M (2003) Short-term continuous enteral tube feeding schedules did not suppress appetite and food intake in healthy men in a placebo-controlled trial. J Nutr 133, 2570-2576.

20. Stratton RJ, Stubbs RJ \& Elia M (2008) Bolus tube feeding suppresses food intake and circulating ghrelin concentrations in healthy subjects in a short-term placebo-controlled trial. Am J Clin Nutr 88, 77-83.

21. Fogg L (2007) Home enteral feeding part 1: an overview. Br J Community Nurs 12, 246-252.

22. Coben RM, Weintraub A, DiMarino AJ, et al. (1994) Gastroesophageal reflux during gastrostomy feeding. Gastroenterology 106, 13-18.

23. Rhoney DH, Parker D, Formea CM, et al. (2002) Tolerability of bolus versus continuous gastric feeding in brain-injured patients. Neurol Res 24, 613-620.

24. Hiebert JM, Brown A, Anderson RG, et al. (1981) Comparison of continuous vs intermittent tube feedings in adult burn patients. J Parenter Enteral Nutr 5, 73-75.

25. Evans DC, Forbes R, Jones C, et al. (2016) Continuous versus bolus tube feeds: does the modality affect glycemic variability, tube feeding volume, caloric intake, or insulin utilization? Int $J$ Crit Care Emerg Med 6, 9.

26. Lee JSW \& Auyeung TW (2003) A comparison of two feeding methods in the alleviation of diarrhoea in older tube-fed patients: a randomised controlled trial. Age Ageing 32, 388-393.
27. Lee J, Kwok T, Chui P, et al. (2010) Can continuous pump feeding reduce the incidence of pneumonia in nasogastric tubefed patients? A randomized controlled trial. Clin Nutr 29, 453-458.

28. NICE (2006) Nutrition support in adults: oral nutrition support, enteral tube feeding and parenteral nutrition (Clinical Guideline 32). https://www.nice.org.uk/guidance/CG32 (accessed September 2019).

29. Black AE, Coward WA, Cole TJ, et al. (1996) Human energy expenditure in affluent societies: an analysis of 574 doublylabelled water measurements. Eur J Clin Nutr 50, 72-92.

30. Wong E, Booth A, Burke M, et al. (2018) A survey of the use of bolus tube feeding in paediatric patients receiving home enteral tube feeding in the UK. J Pediatr Gastroenterol Nutr 66, 1045

31. Hubbard G, Finch H, White S, et al. (2010) A survey of enterally tube fed patients receiving low energy tube feeding regimens. Proc Nutr Soc 69, E523 (OCE7).

32. Hubbard G, Finch H, White S, et al. (2011) A survey of enterally tube fed patients receiving $\sim 800 \mathrm{kcal} / \mathrm{d}$ tube feeding regimens. Proc Nutr Soc 70, E313 (OCE5).

33. Evill R, Berry J, Marjoram H, et al. (2018) A third of paediatric home enterally tube fed patients receive low energy feeding regimens: results of a UK survey. J Pediatr Gastroenterol Nutr 66, 923.

34. Evill RH, Smith TR \& Stratton RJ (2017) MON-P103: characteristics of home enterally tube fed patients with head and neck cancer in the UK. Clin Nutr 36, S217.

35. Silver HJ, Dietrich MS \& Murphy BA (2007) Changes in body mass, energy balance, physical function, and inflammatory state in patients with locally advanced head and neck cancer treated with concurrent chemoradiation after low-dose induction chemotherapy. Head Neck 29, 893-900.

36. Couch M, Lai V, Cannon T, et al. (2007) Cancer cachexia syndrome in head and neck cancer patients: part I. Diagnosis, impact on quality of life and survival, and treatment. Head Neck 29, 401-411.

37. Nutricia (2017) Bolus Feeding in Adults: A Practical Guide. https://www.nutriciahcp.com/adult/Studies/Bolus_feeding_in_ Adults_A_Practical_Guide/\# (accessed September 2019).

38. MacLeod JB, Lefton J, Houghton D, et al. (2007) Prospective randomized control trial of intermittent versus continuous gastric feeds for critically ill trauma patients. $J$ Trauma Acute Care Surg 63, 57-61.

39. Serpa LF, Kimura M, Faintuch J, et al. (2003) Effects of continuous versus bolus infusion of enteral nutrition in critical patients. Rev Hosp Clin Fac Med Sao Paulo 58, 9-14.

40. Maurya I, Pawar M, Garg R, et al. (2011) Comparison of respiratory quotient and resting energy expenditure in two regimens of enteral feeding-continuous vs. intermittent in head-injured critically ill patients. Saudi J Anaesth 5, 195.

41. Brotherton A, Abbott J \& Aggett P (2006) The impact of percutaneous endoscopic gastrostomy feeding upon daily life in adults. J Hum Nutr Diet 19, 355-367. 